\title{
The effectiveness of acaricidic drugs based on herbal raw material
}

\author{
Nataliya Voronova, Valeriy Horban, Viktoriia Bohatkina ${ }^{\star}$ \\ Zaporizhzhia National University, 66 Zhukovsky St, UA-69600 Zaporizhzhia, Ukraine \\ *corresponding author e-mail: v.bohatkina@gmail.com
}

Received: 14 August 2021 / Accepted: 25 November 2021

\begin{abstract}
Limitation in the number of ixodes ticks is one of the most important tasks of modern science and requires the search for new, highly effective and environmentally hazardous acaricides, so our experiment was aimed at identifying acaricidal properties of essential oils and their individual active components in the population of ixodes ticks in Zaporizhzhia region. The study of acaricidal properties of essential oils was performed in the laboratory conditions. Tampons with wool were soaked in various concentrations of $0.5 \%, 1 \%, 3 \%, 5 \%$ and $10 \%$ aqueous emulsion of essential oils such as Caryophyllus floris aetheroleum and Limonis aetheroleum, and essential oils of Thymus serpyllum L., Pinus sylvestris L., Salvia officinalis L., Mentha x piperita L. and Eucalyptus viminalis Labill. The essential oils had a significant effect on the lifespan of adult ticks. The results showed the acaricidal effect of Thymus serpyllum essential oils. When searching the acaricidal and repellent properties of individual essential oils components thymole, menthol and citral showed the high activity as acaricides. At the same time, eugenol and borneol proved the effectiveness as repellent. Our research showed that essential oils are promising as alternative methods of controlling the number of Ixodes ticks in areas where there are conditions for infection with tick infections.
\end{abstract}

Keywords: Ixodes ticks, acaricides, repellents, essential oils, Thymus serpyllum.

\section{Introduction}

The rapid global changes facing our planet, especially those mediated by human activity, significantly affect the epidemiology and course of infectious diseases. This also applies to the diseases, the pathogens of which are transmitted by ixodes ticks since the milder climate affects their further spreadness (Lindgren et al., 2000; Gray et al., 2009; Ogden \& Lindsay, 2016). Ixodes began to actively explore the new ecological niches. It has increased the possibility of human contact with this disease carrier and their probability of being infected by pathogens of transmissible infections (Allen et al., 2017).

According to the epidemiological studies on the incidence of Lyme borreliosis which were conducted in various European countries, mainly the Central Europe has the highest incidence of this disease (Andreychyn et al., 2017). The Ukrainian scientists analyzed the epidemiological situation regarding the incidence of Lyme borreliosis on the territory of Ukraine. The results of this research revealed the natural foci in 8 regions. Biletska and others found out that the main vector of spreadness of these pathogens appeared to be the Ixodes ricinus (Biletska et al., 2008). In Zaporizhzhia region were also created the favorable conditions for infectioning with pathogens that are transmitted by ixodes ticks, namely the Lyme borreliosis, tick-borne (vernal) encephalitis, Crimean-Congo haemorrhagic fever (CCHF), West Nile virus and Batai orthobunyavirus (BATV) (Voronova et al., 2009).

Therefore, a problem of successful control of ixodes ticks occupies the important place in veterinary medicine and requires the searching of new highly effective ascaricidic drugs. In addition, it is necessary to constantly improve the control methods taking into consideration the biology and ecology of ixodes ticks massively attack farm humans and domestic animals. Currently, the use of synthetic drugs 
against the acaricidic ones in the fight against the ixodidae appeared to be the most effective. Their use can significantly reduce the population of these parasites (Malik et al., 2021).

Modern anti-acaricidal drugs are divided into 3 types:

- Repellents, characterized by the fact that only scare away the ticks;

- Ascaricidic, can kill the ticks; in this case, the active ingredients are permethrin, alphamethrin, diazinon, linden and others.

- Insecticidal-repellent, the drugs of combined action which not only scare away the parasites but also can kill them.

These drugs usually include amitraz, fipronil, metaflumizon, pesticides of the methrin group (cypermethrin, delta-methrin) and others.

The recent studies suggest that overuse of synthetic acaricides has led to the environmental pollution problems and further development of resistance within the target tick populations. And it really appeared to be the environmental problem (Naqqash et al., 2016). The scientists are increasingly finding resistance of ixodes towards the certain types of acaricides (Castro-Janer et al., 2010; Mangia et al., 2018).

Taking into consideration this fact, the limitation of number of ixodes ticks is one of the most important tasks of veterinary science and it requires the searching for new environmentally friendly and highly effective acaricides (ElSeedi et al., 2017; Stefanidesova et al., 2017). It is believed that the use of the plant extracts can reduce the resistance of ticks towards the acaricidal products (Díaz et al., 2019). Therefore, the use of the vegetable essential oil in tick control is rather promising and this fact is confirmed by studies of scientists from various countries (Jaenson Palsson et al., 2006; Stefanidesova et al., 2017; Elmhalli et al., 2019). There is little information in literature about the acaricidal effect of essential oils and monoterpenes in I. ricinus control and there is no information concerning the Dermacentor marginatus at all. That is why we believe in the utmost importance of the study that could demonstrate the effect of individual components of essential oils on these ectoparasites and prove their environmental safety in order to understand and evaluate the effects of introduction of such drugs.

It is known from the literature that the composition of essential oils depends on the age of the plant, season and climatic conditions, i.e it depends on the growth conditions in general (Rashidi et al., 2019). Based on this fact, we are convinced that the creation of modern, safe and effective repellent-acaricidal drugs should be comprehensive and in the future it will be possible to provide the opportunity to obtain the product standardization.

Thus, the aim of our study was to identify the effective concentration of essential oils that can exhibit acaricidal activity against imago ticks. We also had to determine the dominant compounds of the component composition of the light fraction of essential oils, which can be considered to be the potential acaricides, following the further testing of this hypothesis.

\section{Material and methods}

The object of our study were the hungry females of ixodes ticks which were collected on the Zaporizhzhia region territory. The collection of adult instars was carried out according to generally accepted method on the flag (Rulison et al., 2013). During this picking was recorded the species composition of the plants from which these ticks were collected. Thus, it was noticed which of the plants the ticks prefer and which of them are completely ignored by them.

In the laboratory, the hungry ticks were placed into the $10 \mathrm{ml}$ test tubes with a cap in which previously was placed a piece of wet sterile bandage. On the test tube was recorded the place of collection, date and time and was conducted the identification of ticks by the determinant (Emchuk, 1960). In order to research the ability to detect acaricidal activity were used the essential oils obtained by steam distillation from the plant raw materials collected in the habitats of ixodes ticks in natural and artificial biogeocenoses on the territory of Zaporizhzhia region: the sage (Salvia officinalis), the creeping thyme (Thymus serpyllum), the Scots pine (Pinus sylvestris) and the peppermint (Mentha $\mathrm{x}$ piperita) as well as from the raw eucalyptus rod (Eucalyptus viminalis) which was purchased at the pharmacy (the country of origin is Georgia) and the commercially available essential oils of clove (Caryophylls floris aetheroleum) and lemon (Limonis aetheroleum).

With the purpose of separation, identification and quantification of certain components in essential oils, we used the gas chromatography with the flame ionization detector "Agilent Technology" (Model 8890) that quickly identifies the number of components present in complex systems containing many light components. In order to separate the light substances was used the capillary column made of fused quartz. Its inner diameter is $0.25 \mathrm{~mm}$, the film thickness is $0.25 \mathrm{~mm}$ and the length is $60 \mathrm{~m}$. The temperature programming was $65^{\circ} \mathrm{C}(10 \mathrm{~min})$, then it was from $65^{\circ} \mathrm{C}$ up to $220^{\circ} \mathrm{C}$ and was kept at the temperature of $220^{\circ} \mathrm{C}$ for $10 \mathrm{~min}$. The temperature of the injector was maintained at the level of $220^{\circ} \mathrm{C}$ and as the carrier gas was used helium at a flow rate of $1.5 \mathrm{ml} / \mathrm{min}$ with the separation of $1: 100$.

The identification of substances was performed by the time retention of standard samples (Sigma-Aldrich).

The essential oils with already explored composition were diluted in water containing $2.0 \%$ of emulsifying agent (SPEN 80) and propylene glycol in necessary concentration. The solutions were stored at $5.0 \pm 2.0^{\circ} \mathrm{C}$. Before using it in 
the experiment, the vial was shaken vigorously for $2 \mathrm{~min}$. Using the spray and making one click equal to $0.5 \mathrm{~g}$, the drug was applied to the wool of the animal which was placed in a chemical box with a diameter of $7 \mathrm{~cm}$. In each cup with wool being pre-treated with a solution of diluted drug, 10 live ixodes ticks were placed. Then, it was covered with a lid and incubated at temperature of $25 \pm 1^{\circ} \mathrm{C}$ at a relative humidity of $65 \pm 5 \%$ and 12 hours' photo period. Along with it was conducted the control experiment. All experiments were carried out in five analytical biological replicates. The acute toxicity was established by the method of diluting the essential oils with concentration of $0.5 \%, 1 \%, 3 \%, 5 \%$ and $10 \%$.

During this experiment was taken into consideration the general condition and death of the ticks. It was calculated the percentage of ticks' death under the action of the drug depending on its concentration and the time of observation.

The viability of ixodes ticks was determined under binoculars (manufactured in Russia/MBS-10), namely, was taken into consideration the mobility of ticks by their irritation with a needle.

To assess the possible toxic effects of individual components against females I. ricinus and D. marginatus, we used each of the components separately, applying the active ingredients produced by Sigma Aldrich. The female mortality was studied at the $5 \%$ level of concentration with the repulsion at $0.5 \%$. The results were recorded within a period per a day. In the first half of the day the count of dead ticks was performed every hour. The end point was taken as 24 hours. Those ticks which did not react to stimuli were considered to be dead.

The measurement results were processed using the program PAST 3.25. To assess the reliability of the detected changes, ANOVA analysis of variance was used to compare the results with the control group. The differences in the probability of the null hypothesis $\mathrm{P} \leq 0.05$ were considered to be significant. The obtained results are presented at the mean value \pm standard error of the mean.

\section{Results}

In the control group of ticks of both species (Table 1), we observed two types of behavior that is the dormancy and the active crawling on the wool. It means that our ticks were active, more or less mobile and able to attack.

After the treatment of wool with the studied essential oils we noticed the locomotion of ticks from the source of odor stimulation (the repellent effect). During the ticks' observation being under the action of essential oils we noticed their suppression. The ticks were less active and almost had no reaction to stimuli. The changes described above indicate to the decrease of the activity of ticks and, in its turn, being under the action of drugs the ticks become less epidemiologically dangerous.

The very interesting exception to this rule appeared to be the essential oil of pine against I. ricinus females. This drug influenced them as an attractant. As far as the acaricidal effect of D. marginatus is concerned, it appeared to be rather low. But it should be noted that at close contact and high concentration together with a long-term action the ticks had a low mortality rate.

The ability to detect acaricidal properties against the hungry adult ticks of $I$. ricinus and D. marginatus is shown in Table 1.

The analysis of statistical characteristics showed the level of significance of ANOVA ( $p=<0.0001)$. These are significant differences in estimates of the species of ticks, the concentration of active substance and exposure time for 4 of kind essential oils, including Eucalyptus viminalis, Salvia officinalis, Thymus serpyllum and Mentha x piperita, all other types of essential oils had a low level of significance ( $p>0.05)$, indicating a negligible difference.

The Creeping thyme essential oil has the greatest acaricidal effect (very high mortality rate in a short time). The highest mortality rates of more than $50 \%$ were observed in all the tested doses of thyme oil $(0.5 \%, 1 \%, 3 \%, 5 \%$ and $10 \%)$, and this toxicity was observed as early as 30 minutes after the start of the experiment (Figs 1-2).

Thus, a 3\% solution of thyme essential oil for 5 hours was already effective for ticks I. ricinus and for 2 hours for $D$. marginatus (Table 1).

The sage essential oil also provoked $100 \%$ mortality using the concentration of emulsions of $3 \%$. At this dosage, the acute toxicity was observed 5 hours after the start of the experiment for females of I. ricinus and 2 hours for females of D. marginatus. The lower concentrations of sage essential oil were also effective, with mite mortality reaching up to $50 \%$ at a concentration of $0.5 \%$ after 5 hours of the experiment. (Table 1).

The peppermint essential oil caused a mortality rate of $100 \%$ at a concentration of $3 \%$ emulsions for both species of ticks.

The least effective acaricides appeared to be the commercial essential oils, the eucalyptus essential oil showed mediocre results, and the clove essential oil proved to be more like a repellent (ticks tried to stay away from wool soaked in the drug), ticks were depressed, but the mortality did not occur.

Based on the obtained data, we investigated the qualitative composition of essential oils in order to identify substances that can potentially act as natural acaricides or repellents and can potentially be used as an active ingredient in the development of new acaricides. 
Table 1. The mortality (\%) of adults of hungry females of ixodes ticks I. ricinus and D. marginatus from the action of essential oil ( \pm $\mathrm{SE}, \mathrm{n}=5$ )

\begin{tabular}{|c|c|c|c|c|c|c|c|c|c|c|}
\hline \multirow[b]{2}{*}{$\begin{array}{c}\text { Exposure } \\
\text { time }\end{array}$} & \multicolumn{5}{|c|}{ Mortality of adult females of ixodes ticks I. ricinus } & \multicolumn{5}{|c|}{$\begin{array}{l}\text { Mortality of adult females of ixodes ticks } \\
\text { D. marginatus }\end{array}$} \\
\hline & 30 minutes & 1 hour & 2 hours & 5 hours & 24 hours & 30 minutes & 1 hour & 2 hours & 5 hours & 24 hours \\
\hline control & $0 \pm 0.0$ & $0 \pm 0.0$ & $0 \pm 0.0$ & $0 \pm 0.0$ & $0 \pm 0.0$ & $0 \pm 0.0$ & $0 \pm 0.0$ & $0 \pm 0.0$ & $0 \pm 0.0$ & $0 \pm 0.0$ \\
\hline \multicolumn{11}{|c|}{ Pinus sylvestris } \\
\hline $0.5 \%$ & $0 \pm 0.00$ & $0 \pm 0.00$ & $0 \pm 0.00$ & $0 \pm 0.00$ & $2 \pm 2.20$ & $0 \pm 0.00$ & $0 \pm 0.00$ & $0 \pm 0.00$ & $0 \pm 0.00$ & $0 \pm 0.00$ \\
\hline $1 \%$ & $0 \pm 0.00$ & $0 \pm 0.00$ & $0 \pm 0.00$ & $2 \pm 2.00$ & $4 \pm 2.45$ & $0 \pm 0.00$ & $0 \pm 0.00$ & $0 \pm 0.00$ & $0 \pm 0.00$ & $2 \pm 2.00$ \\
\hline $3 \%$ & $0 \pm 0.00$ & $2 \pm 2.00$ & $2 \pm 2.00$ & $2 \pm 2.00$ & $4 \pm 2.45$ & $0 \pm 0.00$ & $0 \pm 0.00$ & $0 \pm 0.00$ & $2 \pm 2.00$ & $2 \pm 2.00$ \\
\hline $5 \%$ & $0 \pm 0.00$ & $4 \pm 2.45$ & $4 \pm 2.45$ & $6 \pm 2.45$ & $6 \pm 2.45$ & $2 \pm 2.00$ & $4 \pm 2.45$ & $4 \pm 2.45$ & $6 \pm 4.00$ & $10 \pm 3.16$ \\
\hline $10 \%$ & $4 \pm 2.45$ & $6 \pm 2.45$ & $6 \pm 2.45$ & $6 \pm 2.45$ & $6 \pm 2.45$ & $2 \pm 2.00$ & $4 \pm 2.45$ & $6 \pm 4.00$ & $6 \pm 4.00$ & $8 \pm 3.74$ \\
\hline \multicolumn{11}{|c|}{ Eucalyptus viminalis } \\
\hline $0.5 \%$ & $4 \pm 2.45$ & $6 \pm 4.00$ & $8 \pm 3.74$ & $10 \pm 3.16$ & $22 \pm 3.75$ & $10 \pm 0.00$ & $12 \pm 3.74$ & $20 \pm 3.16$ & $34 \pm 2.45$ & $54 \pm 2.45$ \\
\hline $1 \%$ & $6 \pm 4.00$ & $8 \pm 4.90$ & $16 \pm 6.78$ & $22 \pm 5.83$ & $34 \pm 5.10$ & $8 \pm 3.74$ & $14 \pm 2.45$ & $16 \pm 2.45$ & $22 \pm 3.74$ & $44 \pm 2.45$ \\
\hline $3 \%$ & $8 \pm 4.90$ & $14 \pm 4.00$ & $24 \pm 2.45$ & $38 \pm 3.74$ & $56 \pm 2.45$ & $8 \pm 3.74$ & $10 \pm 4.47$ & $24 \pm 5.10$ & $26 \pm 6.78$ & $32 \pm 5.83$ \\
\hline $5 \%$ & $16 \pm 2.45$ & $28 \pm 3.74$ & $34 \pm 4.00$ & $38 \pm 3.74$ & $44 \pm 6.00$ & $40 \pm 3.16$ & $42 \pm 3.74$ & $50 \pm 3.16$ & $66 \pm 2.45$ & $92 \pm 3.74$ \\
\hline $10 \%$ & $44 \pm 2.45$ & $54 \pm 2.45$ & $60 \pm 3.16$ & $72 \pm 2.45$ & $90 \pm 3.16$ & $68 \pm 2.00$ & $70 \pm 0.00$ & $78 \pm 2.00$ & $88 \pm 3.74$ & $94 \pm 2.44$ \\
\hline \multicolumn{11}{|c|}{ Salvia officinalis } \\
\hline $0.5 \%$ & $2 \pm 2.00$ & $4 \pm 2.45$ & $28 \pm 2.00$ & $54 \pm 2.45$ & $94 \pm 2.45$ & $0 \pm 0.00$ & $4 \pm 2.45$ & $14 \pm 4.00$ & $54 \pm 5.10$ & $82 \pm 3.74$ \\
\hline $1 \%$ & $4 \pm 2.45$ & $8 \pm 3.74$ & $28 \pm 3.75$ & $60 \pm 3.16$ & $90 \pm 5.48$ & $2 \pm 2.00$ & $10 \pm 3.16$ & $18 \pm 3.74$ & $42 \pm 3.74$ & $98 \pm 2.00$ \\
\hline $3 \%$ & $6 \pm 4.00$ & $10 \pm 3.16$ & $24 \pm 5.10$ & $58 \pm 3.74$ & $100 \pm 0.00$ & $14 \pm 2.45$ & $22 \pm 2.00$ & $40 \pm 3.16$ & $78 \pm 2.00$ & $100 \pm 0.00$ \\
\hline $5 \%$ & $14 \pm 2.45$ & $24 \pm 2.45$ & $32 \pm 2.00$ & $82 \pm 4.90$ & $100 \pm 0.00$ & $22 \pm 3.74$ & $42 \pm 3.74$ & $48 \pm 4.90$ & $92 \pm 2.00$ & $100 \pm 0.00$ \\
\hline $10 \%$ & $34 \pm 2.45$ & $46 \pm 2.45$ & $62 \pm 4.90$ & $100 \pm 0.00$ & $100 \pm 0.00$ & $28 \pm 2.00$ & $42 \pm 3.74$ & $82 \pm 4.90$ & $98 \pm 2.00$ & $100 \pm 0.00$ \\
\hline \multicolumn{11}{|c|}{ Thymus serpyllum } \\
\hline $0.5 \%$ & $50 \pm 4.47$ & $68 \pm 3.74$ & $76 \pm 4.00$ & $80 \pm 4.47$ & $94 \pm 2.45$ & $64 \pm 4.00$ & $86 \pm 5.10$ & $98 \pm 2.00$ & $100 \pm 0.00$ & - \\
\hline $1 \%$ & $54 \pm 4.00$ & $62 \pm 3.74$ & $76 \pm 5.10$ & $84 \pm 6.00$ & $100 \pm 0.00$ & $72 \pm 3.74$ & $86 \pm 2.45$ & $100 \pm 0.00$ & - & - \\
\hline $3 \%$ & $54 \pm 6.00$ & $74 \pm 7.48$ & $86 \pm 6.00$ & $92 \pm 3.74$ & $100 \pm 0.00$ & $90 \pm 3.16$ & $98 \pm 2.00$ & $100 \pm 0.00$ & - & - \\
\hline $5 \%$ & $76 \pm 4.00$ & $92 \pm 2.00$ & $98 \pm 2.00$ & $100 \pm 0.00$ & - & $100 \pm 0.00$ & - & - & - & - \\
\hline $10 \%$ & $100 \pm 0.00$ & - & - & - & - & $100 \pm 0.00$ & - & - & - & - \\
\hline \multicolumn{11}{|c|}{ Mentha $\mathrm{x}$ piperita } \\
\hline $0.5 \%$ & $26 \pm 2.45$ & $30 \pm 3.16$ & $46 \pm 4.0$ & $60 \pm 3.16$ & $84 \pm 4.00$ & $32 \pm 0.00$ & $36 \pm 4.00$ & $48 \pm 5.83$ & $60 \pm 3.16$ & $84 \pm 2.45$ \\
\hline $1 \%$ & $38 \pm 4.90$ & $56 \pm 4.00$ & $68 \pm 3.74$ & $80 \pm 4.47$ & $94 \pm 2.45$ & $40 \pm 4.47$ & $50 \pm 5.48$ & $62 \pm 5.83$ & $64 \pm 5.10$ & $96 \pm 2.45$ \\
\hline $3 \%$ & $50 \pm 3.16$ & $70 \pm 7.07$ & $80 \pm 3.74$ & $98 \pm 2.00$ & $100 \pm 0.00$ & $54 \pm 6.00$ & $68 \pm 5.83$ & $98 \pm 2.00$ & $100 \pm 0.00$ & - \\
\hline $5 \%$ & $94 \pm 2.45$ & $94 \pm 2.45$ & $96 \pm 2.45$ & $100 \pm 0.00$ & - & $68 \pm 3.74$ & $88 \pm 3.74$ & $98 \pm 2.00$ & $100 \pm 0.00$ & - \\
\hline $10 \%$ & $100 \pm 0.00$ & - & - & - & - & $70 \pm 3.16$ & $94 \pm 2.45$ & $98 \pm 2.00$ & $100 \pm 0.00$ & - \\
\hline \multicolumn{11}{|c|}{ Caryophyllus floris aetheroleum } \\
\hline $0.5 \%$ & $0 \pm 0.00$ & $2 \pm 2.00$ & $4 \pm 2.45$ & $6 \pm 4.00$ & $10 \pm 4.47$ & $0 \pm 0.00$ & $2 \pm 2.00$ & $6 \pm 4.00$ & $6 \pm 4.00$ & $10 \pm 5.48$ \\
\hline $1 \%$ & $0 \pm 0.00$ & $4 \pm 2.45$ & $10 \pm 4.47$ & $10 \pm 4.47$ & $14 \pm 5.10$ & $0 \pm 0.00$ & $4 \pm 2.45$ & $6 \pm 2.45$ & $10 \pm 4.47$ & $12 \pm 5.83$ \\
\hline $3 \%$ & $0 \pm 0.00$ & $4 \pm 2.45$ & $12 \pm 5.83$ & $18 \pm 4.90$ & $20 \pm 4.47$ & $0 \pm 0.00$ & $8 \pm 4.90$ & $10 \pm 4.47$ & $16 \pm 5.10$ & $16 \pm 5.10$ \\
\hline $5 \%$ & $0 \pm 0.00$ & $6 \pm 2.45$ & $10 \pm 4.47$ & $14 \pm 5.10$ & $20 \pm 5.48$ & $2 \pm 2.00$ & $6 \pm 4.00$ & $10 \pm 5.48$ & $10 \pm 5.48$ & $14 \pm 7.48$ \\
\hline $10 \%$ & $0 \pm 0.00$ & $6 \pm 2.45$ & $12 \pm 2.00$ & $16 \pm 4.00$ & $22 \pm 3.74$ & $6 \pm 2.45$ & $6 \pm 2.45$ & $6 \pm 2.45$ & $12 \pm 3.74$ & $20 \pm 6.32$ \\
\hline \multicolumn{11}{|c|}{ Limonis aetheroleum } \\
\hline $0.5 \%$ & $4 \pm 2.45$ & $6 \pm 2.45$ & $16 \pm 2.45$ & $34 \pm 2.45$ & $54 \pm 2.45$ & $0 \pm 0.00$ & $14 \pm 2.45$ & $26 \pm 2.45$ & $34 \pm 2.45$ & $48 \pm 2.00$ \\
\hline $1 \%$ & $2 \pm 2.00$ & $20 \pm 4.47$ & $32 \pm 7.35$ & $52 \pm 6.63$ & $72 \pm 6.63$ & $10 \pm 3.16$ & $26 \pm 2.45$ & $40 \pm 3.16$ & $50 \pm 5.48$ & $62 \pm 3.74$ \\
\hline $3 \%$ & $10 \pm 3.16$ & $26 \pm 2.45$ & $38 \pm 6.63$ & $60 \pm 5.48$ & $74 \pm 5.10$ & $14 \pm 2.45$ & $20 \pm 0.00$ & $26 \pm 2.45$ & $34 \pm 5.09$ & $60 \pm 3.16$ \\
\hline $5 \%$ & $30 \pm 3.16$ & $40 \pm 3.16$ & $54 \pm 5.10$ & $70 \pm 5.48$ & $76 \pm 6.00$ & $16 \pm 6.00$ & $26 \pm 5.10$ & $38 \pm 5.83$ & $50 \pm 6.32$ & $62 \pm 2.00$ \\
\hline $10 \%$ & $26 \pm 2.45$ & $36 \pm 5.10$ & $48 \pm 9.17$ & $70 \pm 3.16$ & $88 \pm 2.00$ & $18 \pm 2.00$ & $36 \pm 2.45$ & $54 \pm 4.00$ & $66 \pm 2.45$ & $74 \pm 2.44$ \\
\hline
\end{tabular}




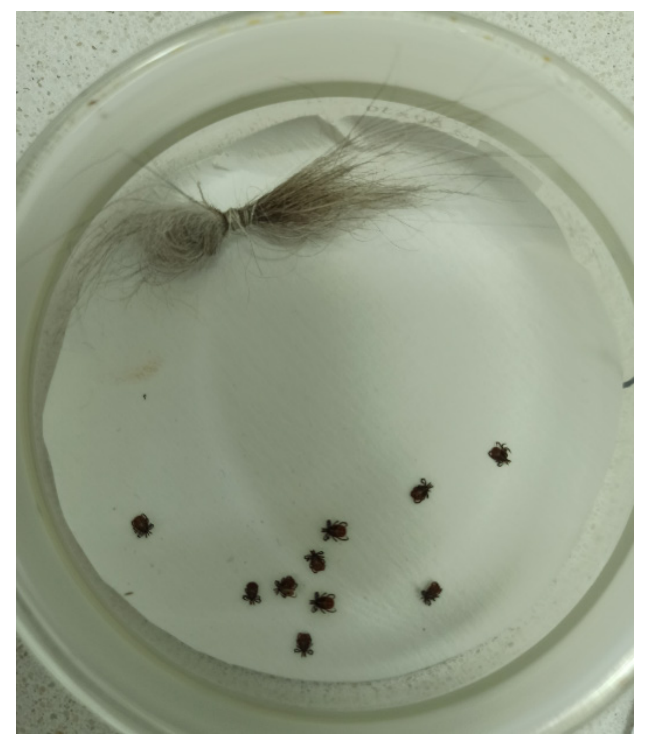

Figure 1. Females I. ricinus under the action of essential oil of Thymus serpyllum

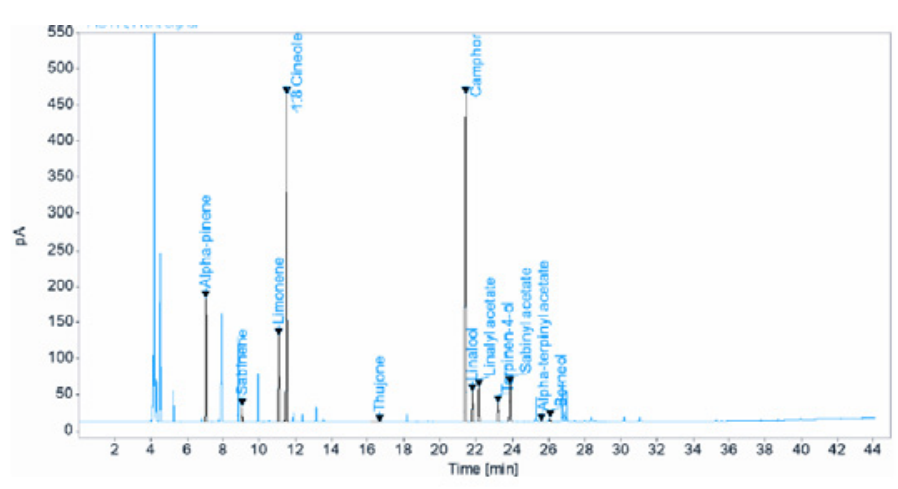

Figure 3. Chromatogram of essential oil Salvia officinalis

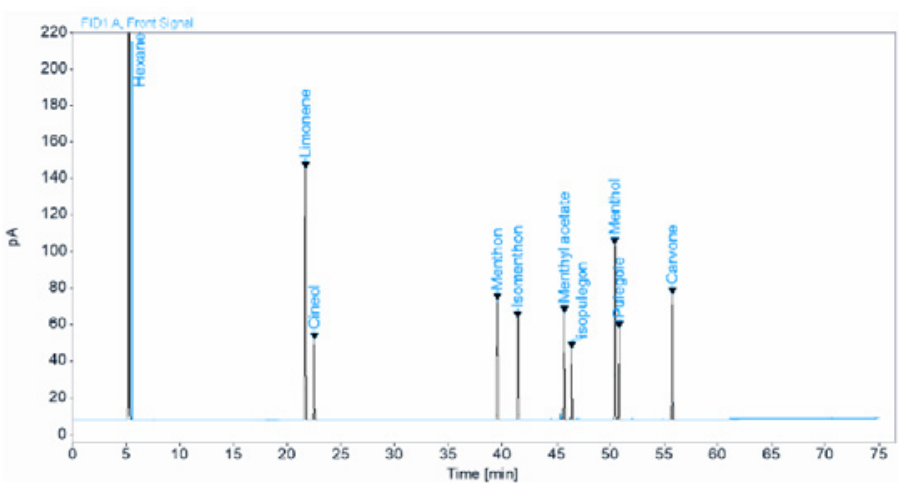

Figure 5. Chromatogram of essential oil Mentha piperita

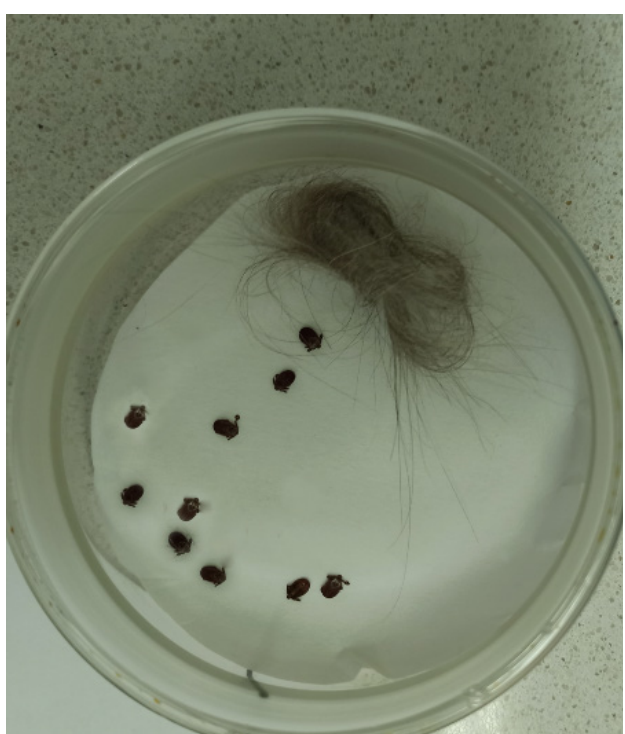

Figure 2. Females of D. marginatus under the action of essential oil of Thymus serpyllum

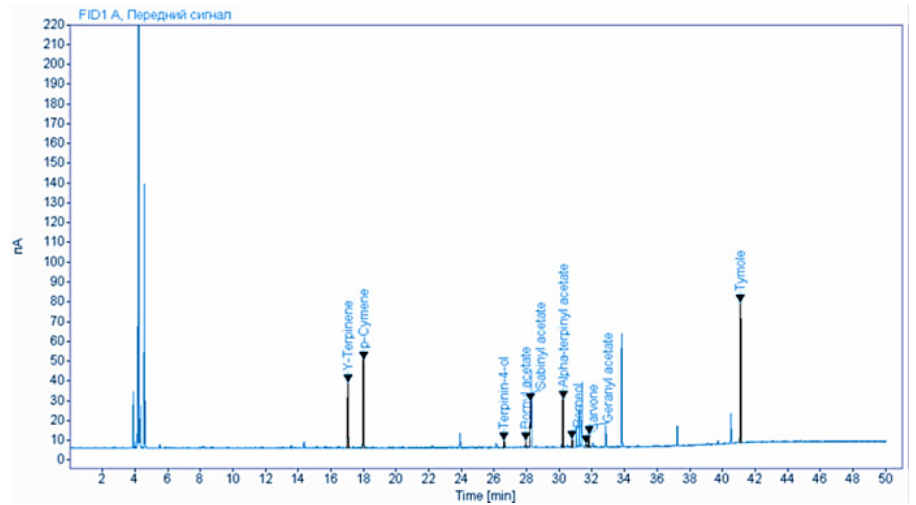

Figure 4. Chromatogramof essential oil Thymus serpyllum

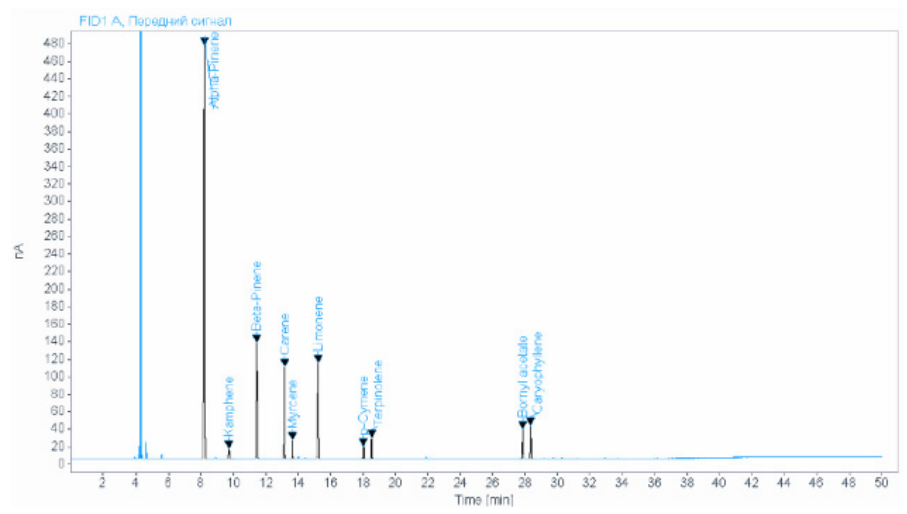

Figure 6. Chromatogram of essential oil Pinus sylvestris 


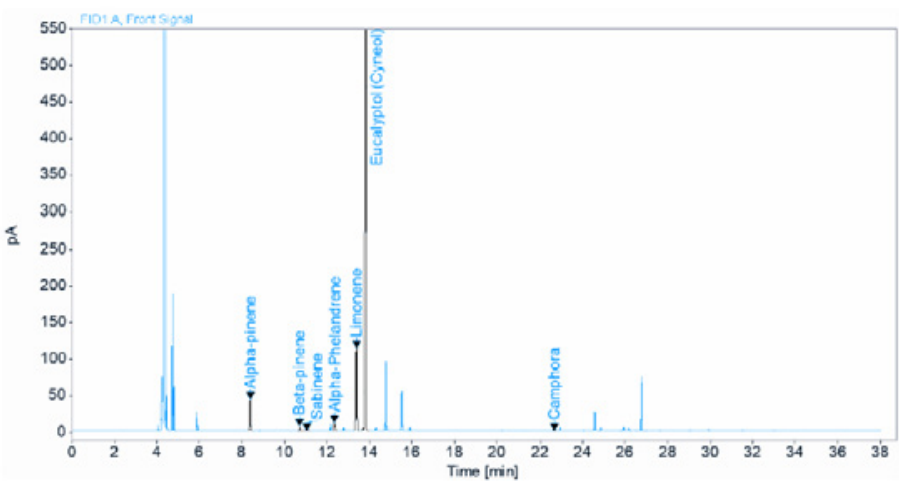

Figure 7. Chromatogram of essential oil Eucalyptus viminalis

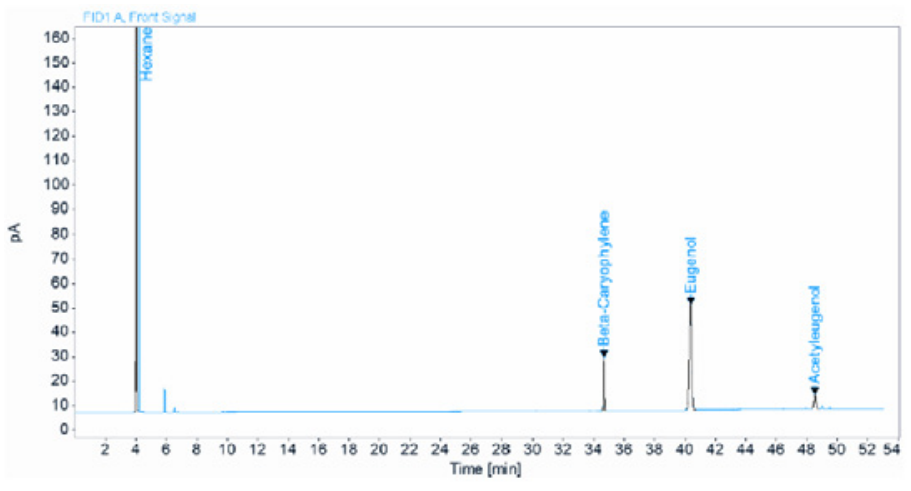

Figure 8. Chromatogram of Caryophyllus floris aetheroleum

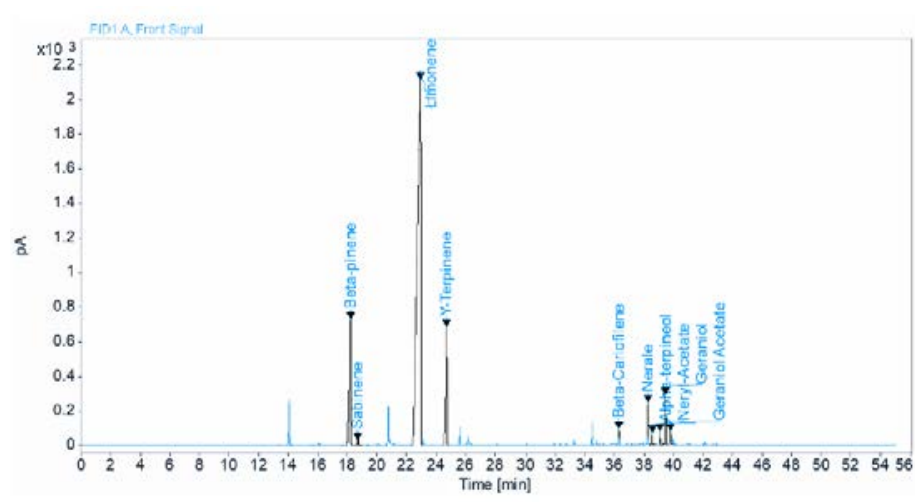

Figure 9. Chromatogram of Limonis aetheroleum

All essential oils were tested for volatile components. The investigated components of essential oils were identified in the process of chromatography by comparison with standard samples (Figs 3-9). Totally about 39 components were identified, most of which were terpenes and a small amount of carboxylic acids (Table 2). Salvia officinalis contain 12 volatile components, which were represented only by monoterpenes, in Caryophyllus floris aetheroleum - we identified 3 components represented by sesquiterpene and carboxylic acids. All the studied oils had a major common group of compounds related to terpenes. The most common monoterpene appeared to be the limonene. It was identified in almost all studied essential oils except the creeping thyme and clove oil, and it was the dominant ingredient in the commercially available lemon essential oil. In the peppermint essential oil, the dominant ingredient was menthol that makes it to be one of the best acaricides. The creeping thyme essential oil has the greatest acaricidal effect (very high mortality rate in a short period of time). This essential oil includes 3 main compounds in its composition mainly Y-terpinene, $\mathrm{p}$-cymene and thymol. The sage oil has proved to be an effective acaricide against adult ixodes ticks, the main compounds in which were eucalyptol and camphora. The interesting fact is that such component as eucalyptol dominates in the essential oil of Eucalyptus viminalis over $86 \%$, but its acaricidal activity is rather moderate, i.e. mite mortality occurred only at high concentrations and long exposure. The Pinus sylvestris essential oil and commercial essential oils showed the lowest acaricidal properties, except for the clove oil, which proved to be more like a repellent with the main substance as eugenol.

While studying the individual components for toxic effects applying to the females I. ricinus and D. marginatus, it was found that as a potential natural acaricide may be thymol, camphor, limonene, menthol and citral. Under the action of these components, $100 \%$ mortality occurred during the day for both species of ticks (Fig. 10). Within the first hour we noticed the depression of their condition (i.e the ticks were inactive and almost did not respond to stimuli).

One of the most promising natural repellents, in addition to the above mentioned components, can be eugenol and borneol, which gave the greatest reaction in avoiding of ticks during the day, comparing to other components that had a similar effect in the first hours, but eventually disappeared (Fig. 11).

The empirical study showed that the most active repellent is thymole, despite the fact that in the first half hour of this drug ticks remained alive (Figs 12-13), while their movement 
Table 2. Qualitative composition of essential oils with quantitative determination of compounds that have been identified in their composition and have the potential for anti-acaricidal effects

\begin{tabular}{|c|c|c|c|c|c|c|c|}
\hline & $\begin{array}{c}\text { Pinus } \\
\text { sylvestris }\end{array}$ & $\begin{array}{l}\text { Mentha } \\
\text { piperita }\end{array}$ & $\begin{array}{c}\text { Salvia } \\
\text { officinalis }\end{array}$ & $\begin{array}{c}\text { Thymus } \\
\text { serphyllum }\end{array}$ & $\begin{array}{c}\text { Eucalyptus } \\
\text { viminalis }\end{array}$ & $\begin{array}{c}\text { Caryophyl- } \\
\text { lus floris } \\
\text { aetheroleum }\end{array}$ & $\begin{array}{c}\text { Limonis } \\
\text { aetheroleum }\end{array}$ \\
\hline \multicolumn{8}{|c|}{ Monoterpenes } \\
\hline Alpha-Pinene & 33.61 & & 11.08 & & 3.14 & & \\
\hline Camphene & 2.97 & & & & & & \\
\hline Beta-Pinene & 7.00 & & & & 0.48 & & 11.69 \\
\hline Carene & 38.73 & & & & & & \\
\hline Myrcene & 0.51 & & & & & & \\
\hline Limonene & 5.89 & 4.74 & 4.69 & & 9.16 & & 73.68 \\
\hline Phellandrene & 0.21 & & & & 0.85 & & \\
\hline Eucalyptol & & & 27.36 & & 86.14 & & \\
\hline Y-Terpinene & & & & 17.41 & & & 8.63 \\
\hline p-Cymene & 2.85 & & & 22.88 & & & \\
\hline Terpinolene & 4.78 & & & & & & \\
\hline Bornyl acetate & 3.31 & & & 1.59 & & & \\
\hline Carvone & & 1.79 & & 1.17 & & & \\
\hline Thymole & & & & 29.73 & & & \\
\hline Sabinene & & & 0.75 & & 0.19 & & 1.26 \\
\hline Camphora & & & 34.75 & & 0.04 & & \\
\hline Nerale & & & & & & & 1.14 \\
\hline Alpha-terpineol & & & & & & & 0.42 \\
\hline Geraniol & & & & & & & 2.02 \\
\hline Borneol & & & 5.12 & 2.03 & & & \\
\hline Menthon & & 30.93 & & & & & \\
\hline Isomenthon & & 11.37 & & & & & \\
\hline Menthyl acetate & & 4.75 & & & & & \\
\hline Isopulegon & & 2.68 & & & & & \\
\hline Menthol & & 41.97 & & & & & \\
\hline Pulegone & & 1.77 & & & & & \\
\hline Thujone & & & 0.31 & & & & \\
\hline Linalool & & & 1.44 & & & & \\
\hline Linalyl acetate & & & 2.4 & & & & \\
\hline Terpinen-4-ol & & & 1.39 & 1.55 & & & \\
\hline $\begin{array}{l}\text { Alpha-terpinyl } \\
\text { Acetate }\end{array}$ & & & 3.71 & 10.65 & & & \\
\hline Sabinyl acetate & & & 7 & 10.21 & & & \\
\hline \multicolumn{8}{|c|}{ Sesquiterpeni } \\
\hline Caryophyllene & 0.14 & & & & & & \\
\hline Beta-Cariofilene & & & & & & 9.50 & 0.19 \\
\hline \multicolumn{8}{|c|}{ Carboxylic acids } \\
\hline Geranyl acetate & & & & 2.78 & & & 0.54 \\
\hline Eugenol & & & & & & 85.1 & \\
\hline Neryl-Acetate & & & & & & & 0.43 \\
\hline Acetyleugenol & & & & & & 5.4 & \\
\hline
\end{tabular}


[62]

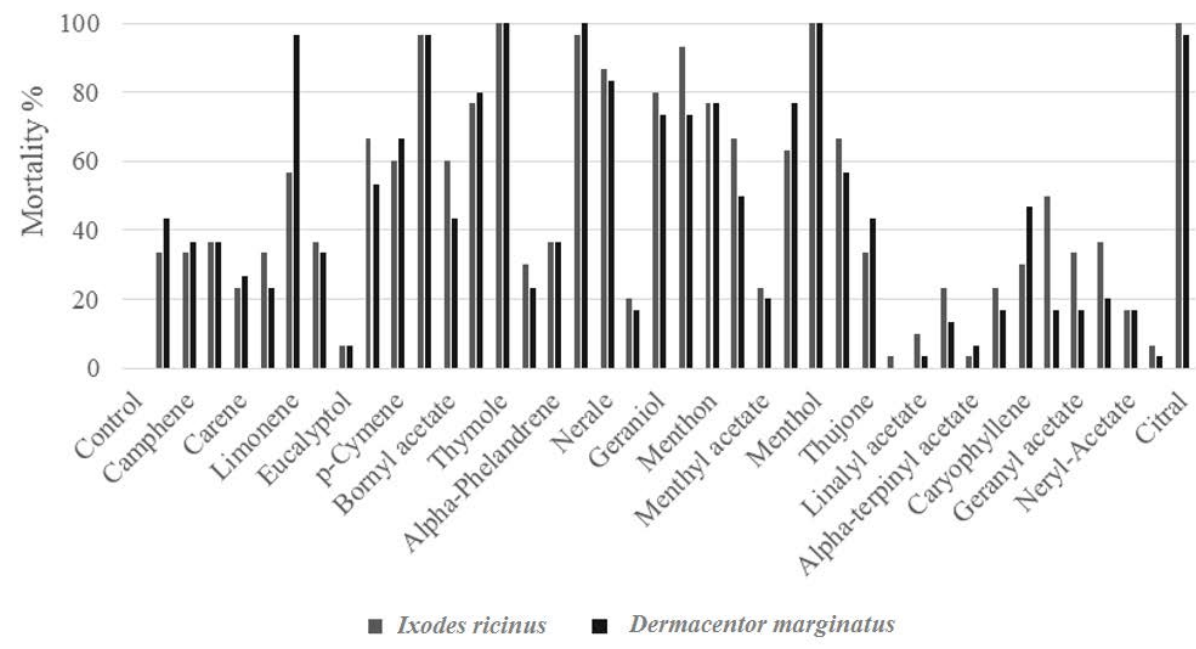

Figure 10. Acaricidal properties of individual components of essential oils against adult ixodes ticks

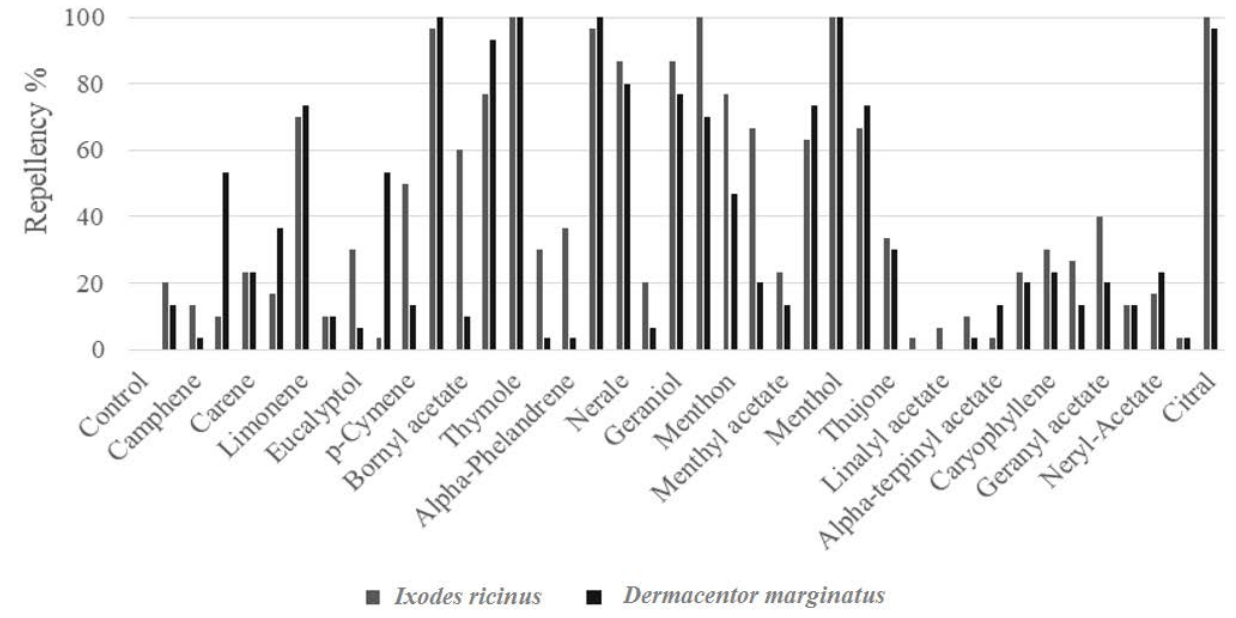

Figure 11. Repellent properties of individual components of essential oils against adult ixodes ticks

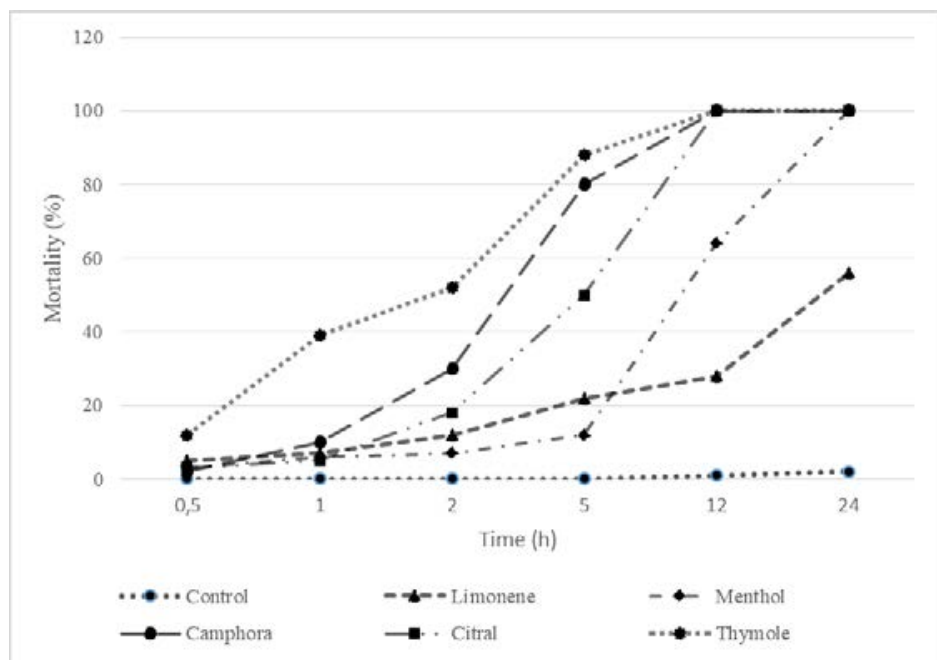

Figure 12. Mortality of female I. ricinus under the influence of active substances of essential oils during 24 hours

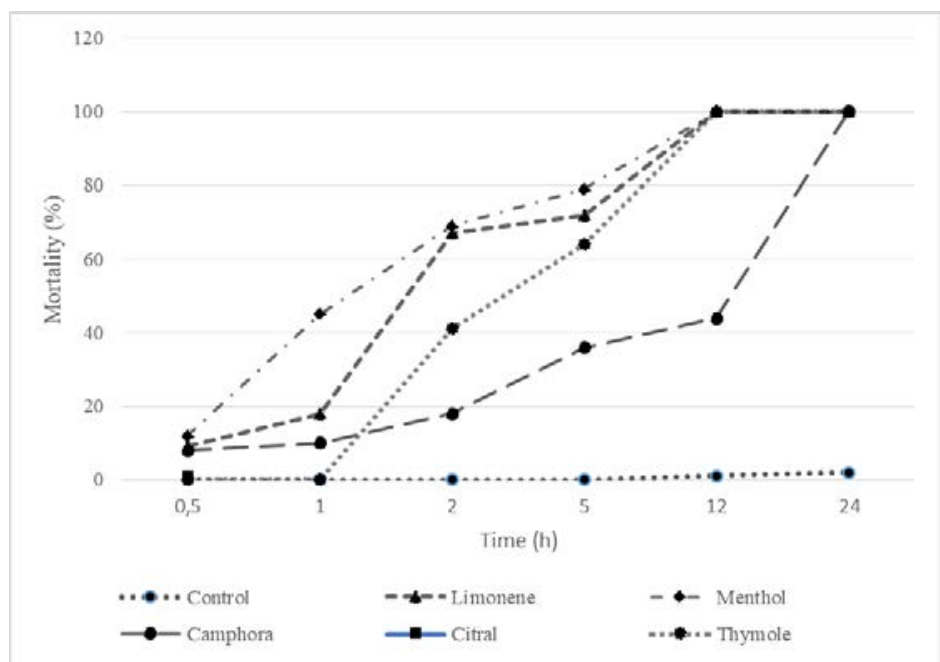

Figure 13. Mortality of females of D. marginatus under the influence of active substances of essential oils within 24 hours 
stopped and dead individuals appeared in the first hours of exposure. Thus, $50 \%$ of LD50 was observed 2 hours after the start of the experiment for I. ricinus ticks (Fig. 12), and for D. marginatus ticks was slightly longer and could last up to 5 hours of the experiment. Already at the 12th hour of the experiment under the action of $5 \%$ solution of thymol, the ticks of both species reached LD100 (Figs 12-13).

As far as such components as menthol, limonene and citral are concerned, they can also be recommended as potential acaricides. Under the action of menthol, the LD100 for D. marginatus was reached within 12 hours, and for I. ricinus the term was increased up to 24 hours. Limonene was effective against D. marginatus ticks and citral was effective against both species of ticks.

Thus, we found out that 3 components have a significant acaricidal effect on females I. ricinus and D. marginatus, namely thymole, menthol and citral, all other components have a less pronounced toxic effect.

\section{Discussion}

For more than a century the control over the number of ixodes ticks has been of a considerable interest to scientists and researchers (Fischer et al., 2013; Dumont et al., 2015). It is now known that the use of chemicals has led to the development of resistance of ixodes ticks to acaricides and the evidence of these facts is increasingly displayed in the modern scientific literature (Abbas et al., 2014). It is known that some plant species contain essential oils which consist of specific volatile components used by the plant as a means of protection against phytophagous (Pichersky \& Gershenzon, 2002), but some of them can act as natural pesticides and repellents (Wong et al., 2021)

One of the first who became interested in this question was a group of scientists from Russia back in 1992. They found out that in pairs of attractants, ixodes ticks increase their body weight and change the time of development to adults while repellents have the opposite effect (Alekseev et al., 1992). Recently, the study of essential oils as regulators of the number of blood-sucking arthropods has developed rapidly around the world (Dorla et al., 2019; Nwanade et al., 2020) but in Ukraine such studies have not been yet conducted enough. Our previous studies have shown that mainly the sage (Salvia officinalis) has very effective repellent properties (Voronova et al., 2016). We continued the search for natural repellents influencing on the adult female ticks of $I$. ricinus among the essential oils of sage, thyme and pine. These substances inhibited the motor activity and led to the death of ixodes ticks with increasing the dose and exposure time (Voronova et al., 2019). This research proved that 3 essential oils are effective acaricides against the hungry female adults of I. ricinus and D. marginatus. Thus, the creeping thyme essential oil had the greatest acaricidal effect (high mortality rate in a short time), eucalyptus essential oil had less effect and the commercial clove oil proved to be a repellent. The similar results were obtained at Stockholm University where the scientists studied the repellent properties of essential oils. Their results showed that among the tested plants the strongest repellent effect on nymphs of I. ricinus was exerted by the oils of citronella, clove and lily of the valley. As far as the essential oil of eucalyptus and mint is concerned, according to their data, the effect disappeared within 4 hours (Thorsell et al., 2006). The longer action of the selected substances can also occur as a part of the tested samples. In our opinion, the effect of repellent or acaricidal activity may disappear with decreasing the concentration of the active substance. So, due to the fact that the essential oil contains the volatile components that exhibit the repellent and acaricidal action to this composition was added the propelene glycol the aim of which was to contain the volatile components in the preparation.

Adenubi et al. (2021) studied the acaricidal activity of the essential oil of one of the species of eucalyptus, namely Eucalyptus globulus Labill. According to their data, the most effective concentration was $10 \%$ solution (Adenubi et al., 2021), which is consistent with our results for another species of eucalyptus, namely Eucalyptus viminalis. The origin of the obtained results may be the similarity of the composition of these essential oils in which the main component was 1.8 cineol (eucalyptol). Thus, the acaricidal or repellent effect is provided by certain elements of the composition of the essential oil of plants, mainly by monoterpenes (Badawy et al., 2010).

A large number of works are devoted to the study of the qualitative composition of essential oils. Thus, Y.I. Korniyevsky together with co-authors with the help of GRH identified 50 components in the creeping thyme, the main of which were thymol $21.92 \%$ and Y-terpinene $17.24 \%$ (Korniyevsky et al., 2019). And the scientists from China have shown that the main components of T. serpyllum essential oil are thymol (41.6\%), p-cymol (21.9\%) and Y-terpinene (19.2\%) (Xie et al., 2020). While, the scientists from Belarus allow the existence of different chemotypes of creeping thyme, as it is reported in their work (Buzuk et al., 2011). They also compared the chromato-mass-spectrometric analysis of creeping thyme and revealed that the main components are camphene, $\beta$-myrcene, 1,8 -cineole. In our experiments, the main component was thymol (Fig. 4). To the studying of the composition of peppermint essential oil were devoted several works. We would like to note the works of scientists from Zaporizhzhia State Medical University who identified 18 compounds, the main of which were menthol, menthol and isomentone (Dolya et al., 1999), and it also 
coincides with our results (Fig. 5). This fact is explained by the collection of material from one study area. Therefore, due to our obtained data, we can confirm the hypothesis that the quantitative content and component composition of oils may vary depending on the type of raw material, the part of the plant from which the analysis is performed and the place of its growth.

Also, in recent years, is going really strong the study of acaricidal properties of volatile components contained in essential oils, along with traditional acaricides (Monteiro et al., 2012; Jia et al., 2018). Thus, M. Tabari and co-authors reported about the better effect of carvacrol and thymol against I. ricinus maggots than permethrin (100\% mortality in 24 hours) (Tabari et al., 2017). It is known that pesticides of the metrin group affect the reproductive system, in particular the ability of females of I. ricinus to lay eggs (Buczek et al., 2019). Also, these pesticides are considered to be neurotoxicants (Pereira et al., 2017), which are also able to change the behavior of ticks during feeding, which affects the duration of this process (Buczek et al., 2015). We believe the behavioral features of ixodes play a significant role in the transmission of pathogens, in particular, the activity of ticks, their mobility and ability to seek and attack their prey and it depends on the effectiveness of transmission of pathogens of various etiologies. Later, Alana Dos Santos Cardoso and co-authors (Cardoso et al., 2020) showed the ability of thymol and carvacrol to inhibit one of the most important central nervous system enzymes acetylcholinesterase, which is similar to the action of classical acaricides, in particular propoxur. Also, thymol affects the reproductive function of females of Rhipicephalus sanguineus thereby suppressing their ability to reproduce (Matos et al., 2020).

It is known that the synthetic acaricides mechanism action on ixodes ticks is different and developing the new drugs, the scientists take into account these features, determining in advance the effectiveness. Thus, the most popular synthetic insecticide-repellent acaricides is fipronil, which is known to affect the nervous system of insects, but P.R. de Oliveira proved the effect of fipronil on the oocytes of female ticks $R$. sanguineus, which in turn affects their fertility (Oliveira et al., 2008). The recent scientific reports indicate that the combination of monoterpenes has shown a synergistic effect on the maggots of Rhipicephalus microplus and R. sanguineus sl. (Araújo et al., 2016) and Dermacentor nitens (Novato et al., 2015), which demonstrates the possibility of developing the highly effective natural acaricides of complex action. Also, in our studies, citral was effective against imago ticks (Figs 1011), this component was identified in commercially available lemon essential oil and consisted of two components geranial and neral, i.e. it was a complex drug. At the same time, it should be noted that the essential oil of lemon showed a moderate acaricidal effect in contrast to citral. In other studies, citral was most effective against $R$. microplus larvae (Peixoto et al., 2015).

As it was previously reported, in Zaporizhzhia region there are conditions for infection with pathogens that transmit ixodes ticks: Lyme borreliosis, tick-borne encephalitis (TB), Crimea-Congo hemorrhagic fever, West Nile fever and Batai virus. In I. ricinus, the antigen of Borrelia and $\mathrm{KE}$ virus was detected in $6.3 \%$ and $13.3 \%$ of the studied individuals, accordingly (Voronova et al., 2011) While many researchers emphasize that Zaporizhzhia region is one of the largest industrial centers in Ukraine and has many environmental problems (Babushkin et al., 2010), there is a need to develop new environmentally friendly natural acaricides and implementation of a modern methodology for regulating the number of parasitic arthropods.

So, based on the above, using the computer modeling (in silico), which is many times more cost-effective than building a physical model, using free and accessible Internet resource (http://www.way2drug.com/gusar/acutoxpredict. html), we analyzed the potential natural acaricides and repellents for acute toxicity on rats (QSAR analysis), by means of the GUSAR software using the structural formulas of substance and evaluated their bioaccumulation (Table 3). The analysis was performed using 2D structural formulas from databases of the PubChem (https://pubchem.ncbi. nlm.nih.gov). Taking into account the calculated values of the bioaccumulation factor (Bioaccumulation factor Log10 BCF) for all identified compounds, we obtained data that are located in the range of $0.88-3.19$, which indicates the low environmental toxicity of these substances. According to the Stockholm Convention on persistent organic pollutants (Appendix D), the BCF should not exceed 4 units (The Stockholm Convention on Persistent Organic Pollutants was adopted on 22 May 2001 in Stockholm, Sweden).

Comparison of the obtained data on acute toxicity to rats show that most of compounds belong to 4 th and hazard class 5 th, and linalyl acetate has no toxic effects (Table 3 ).

According to the obtained data we can conclude that the potential natural acaricides meet the criteria of pesticides of "low risk".

\section{Conclusions}

In the process of studying the toxicity of natural compounds against adult ixodes ticks, it was found out that the most promising active ingredients can act the compounds that are the part of such essential oils as Salvia officinalis, Mentha $\mathrm{x}$ piperita and Thymus serpyllum.

The essential oil of the creeping thyme has the greatest acaricidal effect (very high mortality rate within a short period of time). 
Table 3. QSAR-analysis for natural potential acaricides

\begin{tabular}{|c|c|c|c|c|c|c|c|}
\hline & $\begin{array}{l}\text { Bioaccumu- } \\
\text { lation factor } \\
\text { Log10 BCF }\end{array}$ & \begin{tabular}{|c} 
Daphnia \\
magna \\
LC50-Log10 \\
mol/L \\
\end{tabular} & \begin{tabular}{|c} 
Fathead \\
Minnow \\
LC50-Log10 \\
mmol/L \\
\end{tabular} & $\begin{array}{c}\text { Tetrahymena } \\
\text { pyriformis } \\
\text { IGC50-Log10 } \\
\text { mol/L }\end{array}$ & $\begin{array}{c}\text { Rat Oral } \\
\text { LD50 } \\
(\mathrm{mg} / \mathrm{kg})\end{array}$ & $\begin{array}{c}\text { Rat SC LD50 } \\
(\mathrm{mg} / \mathrm{kg}\end{array}$ & $\begin{array}{c}\text { Classification } \\
\text { at Oral } \\
\text { LD50/Rat } \\
\text { SC LD50 } \\
\end{array}$ \\
\hline & \multicolumn{7}{|c|}{ Monoterpenes } \\
\hline Alpha-Pinene & 3.194 & 4.368 & -1.985 & 0.843 & 3002 & 284.2 & $5 / 4$ \\
\hline Camphene & 2.175 & 4.117 & -1.702 & 0.826 & 2036 & 282.5 & $5 / 4$ \\
\hline Beta-Pinene & 2.389 & 4.205 & -1.873 & 0.762 & 2172 & 366.6 & $5 / 4$ \\
\hline 3-Carene & 2.842 & 4.229 & -1.720 & 0.623 & 2799 & 485.6 & $5 / 4$ \\
\hline Myrcene & 2.319 & 5.322 & -2.722 & 0.861 & 2161 & 626.1 & $5 / 4$ \\
\hline Limonene & 2.163 & 4.766 & -1.906 & 0.609 & 2167 & 162.1 & $5 / 4$ \\
\hline Phellandrene & 3.089 & 4.772 & -1.939 & 0.949 & 2872 & 238.0 & $5 / 4$ \\
\hline Eucalyptol & 1.377 & 3.671 & -0.284 & 0.037 & 2480 & 314.9 & $5 / 4$ \\
\hline Y-Terpinene & 2.602 & 4.411 & -1648 & 0.742 & 2481 & 299.6 & $5 / 4$ \\
\hline p-Cymene & 2.571 & 4.189 & -1.444 & 0.655 & 2786 & 511.7 & $5 / 4$ \\
\hline Terpinolene & 2.340 & 4.390 & -1.445 & 0.745 & 3949 & 647.1 & $5 / 4$ \\
\hline
\end{tabular}


Table 3. continue

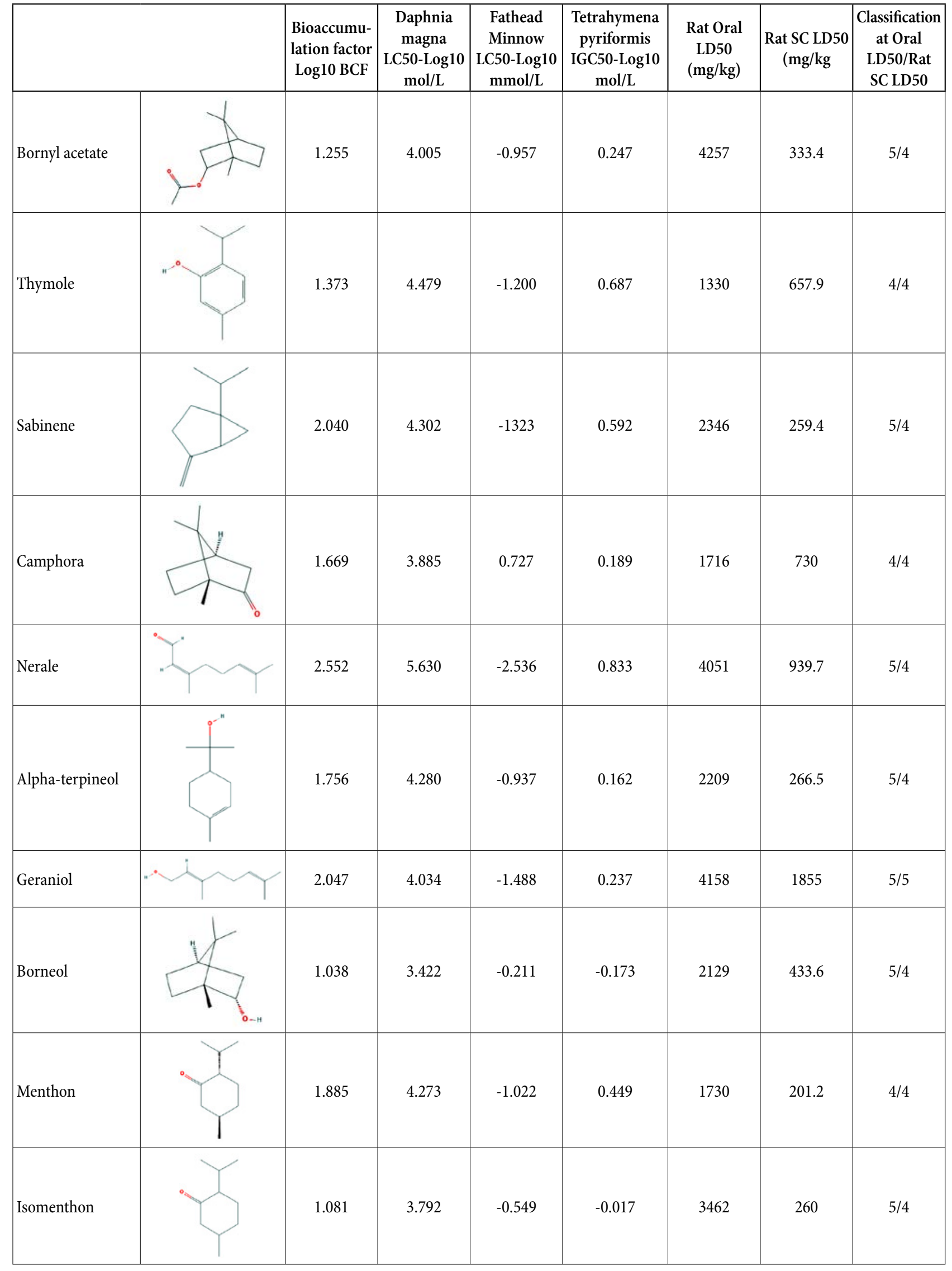


Table 3. continue

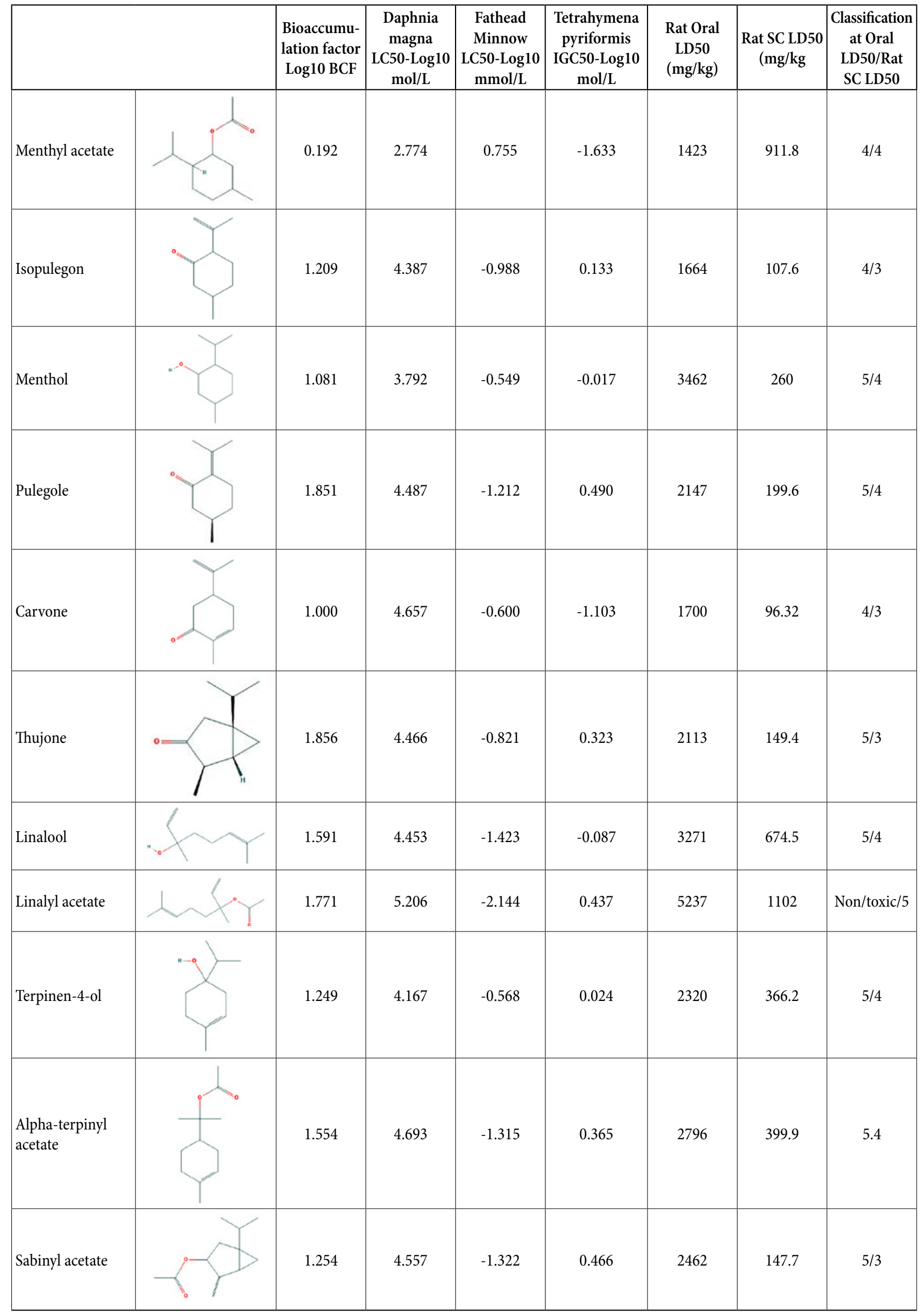




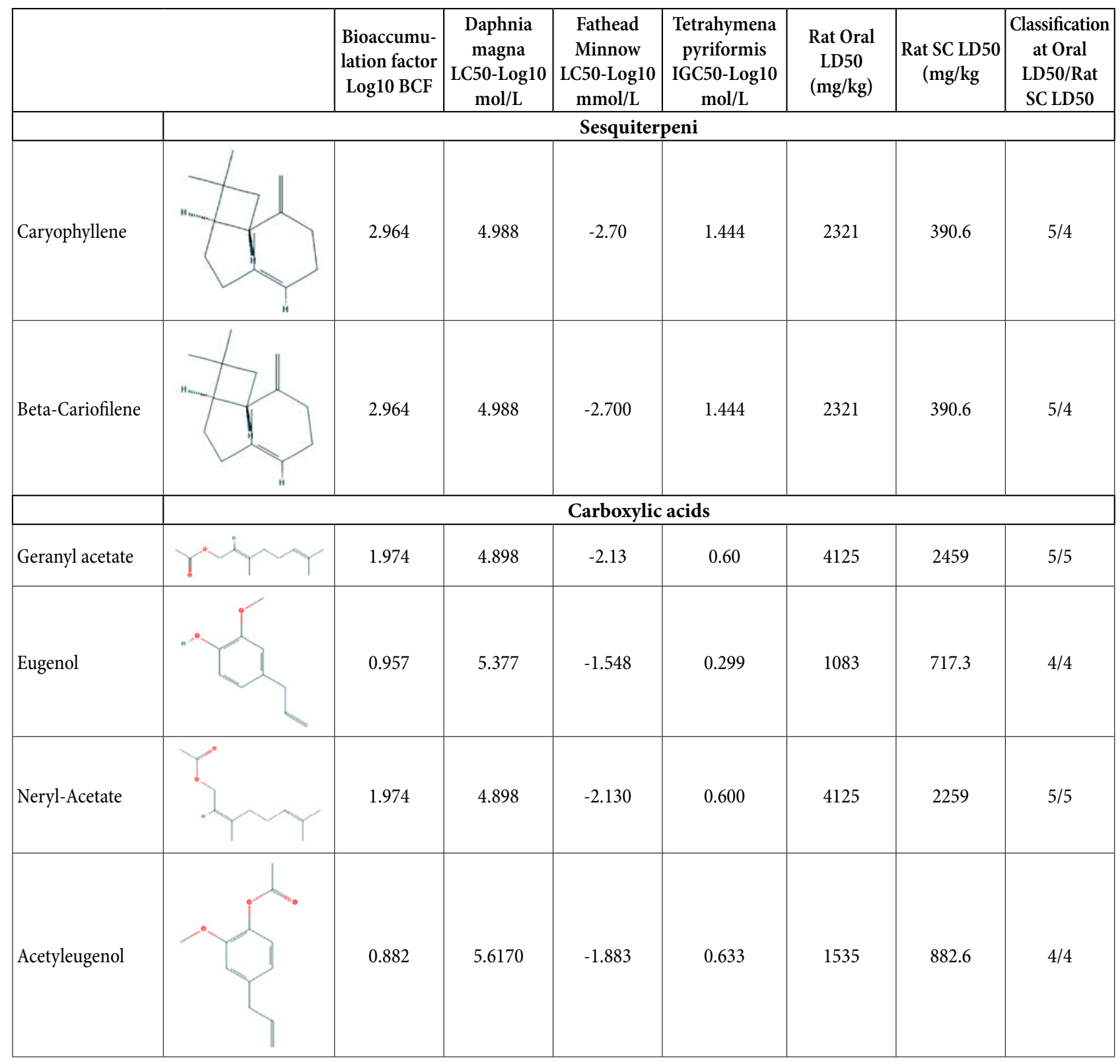

Thymole, menthol and citral as acaricides and eugenol, borneol as repellents have shown a good activity during the study of acaricidal and repellent properties among the individual components of the composition of essential oils.

The results of our research can be taken into account in the process of creation of new combined drugs and it can be used as an alternative to conventional chemical acaricides in control of Ixodes.

Taking into consideration the acaricidal and repellent activity of the individual components, it is necessary to conduct the further research in order to study the mechanism of action of each represented components and to assess the susceptibility of ticks towards these natural products directly in the field.

The obtained results can give a new understanding of the possible use of essential oils as a part of acaricidal and repellent drugs with low impact on the environment, as well as human and animal health.

\section{References}

Abbas R.Z., Zaman M.A., Colwell D.D., Gilleard J. \& Iqbal Z., 2014, Acaricide resistance in cattle ticks and approaches to 
its management: The state of play. Veterinary Parasitology 203: 6-20.

Abouhosseini Tabari M., Youssefi M., Maggi F. \& Benelli G., 2017, Toxic and repellent activity of selected monoterpenoids (thymol, carvacrol and linalool) against the castor bean tick, Ixodes ricinus (Acari: Ixodidae). Veterinary Parasitology 245: 86-91.

Adenubi O.T., Abolaji A.O., Salihu T., Akande F.A. \& Lawal, H., 2021, Chemical composition and acaricidal activity of Eucalyptus globulus essential oil against the vector of tropical bovine piroplasmosis, Rhipicephalus (Boophilus) annulatus. Experimental and Applied Acarology 83: 301-312.

Alekseev A.N., Burenkova L.A. \& Chunikhin S., 1992, Plant odors as determinants of behaviour and development rate of ixodids, vector of diseases. Parazitologia 26: 20-32.

Allen H.C., Welliver R.C., Fogarty M.W., Gessouroun M.E. \& Henry E.D., 2017, Intravenous Immunoglobulin Therapy for Cerebral Vasculitis Associated with Rocky Mountain Spotted Fever. Journal of Pediatric Intensive Care 6: 142-144.

Andreychyn M., Pańczuk A., Shkilna M., Tokarska-Rodak M., Korda M., Kozioł-Montewka M. \& Klishch I., 2017, Epidemiological situation of lyme borreliosis and diagnosis standards in Poland and Ukraine. Health Problems of Civilization 11: 190-194.

Araújo L.X., Novato T.P.L., Zeringota V., Maturano R., Melo D., Da Silva B.C., Daemon E., De Carvalho M.G. \& Monteiro C.M.O., 2016, Synergism of thymol, carvacrol and eugenol in larvae of the cattle tick, Rhipicephalus microplus, and brown dog tick, Rhipicephalus sanguineus. Medical and Veterinary Entomology 30: 377-382.

Babushkin G.F., Kuzkin O.F., Judin V.P. \& Padchenko E.A., 2010, Transport-environmental problems of Zaporizhye. New Materials and Technologies in Metallurgy and Mechanical Engineering 1: 144-146.

Badawy M.E.I., El-Arami S.A.A. \& Abdelgaleil S.A.M., 2010, Acaricidal and quantitative structure activity relationship of monoterpenes against the two-spotted spider mite, Tetranychus urticae. Experimental and Applied Acarology 52: 261-274.

Biletska H., Podavalenko L., Semenyshyn O., Lozynskyj I. \& Tarasyuk O., 2008, Study of Lyme borreliosis in Ukraine. International Journal of Medical Microbiology 298: 154-160.

Buczek A., Bartosik K., Buczek W., Buczek A.M. \& Kuczyński P., 2019, The effect of sublethal concentrations of deltamethrin and alphacypermethrin on the fecundity and development of Ixodes ricinus (Acari: Ixodidae) eggs and larvae. Experimental and Applied Acarology 78: 203-221.
Buczek A., Lachowska-Kotowska P. \& Bartosik K., 2015, The effect of synthetic pyrethroids on the attachment and host-feeding behaviour in Dermacentor reticulatus females (Ixodida: Amblyommidae). Parasites \& Vectors 8, Article number: 366.

Buzuk A.G., Jurchenko R.A., Vinarskiy V.A. \& Buzuk G.N., 2011, Comparative pharmacognostical analysis of grass thyme. Vestnik of Vitebsk State Medical University 3(53): 19-24 (in Russian).

Cardoso A.S., Santos E.G.G., Lima A.D.S., Temeyer K.B., Pérez De León A.A., Costa L.M. \& Martins A., 2020, Terpenes on Rhipicephalus (Boophilus) microplus: Acaricidal activity and acetylcholinesterase inhibition. Veterinary Parasitology 280: 109090.

Castro-Janer E., Martins J.R., Mendes M.C., Namindome A., Klafke G.M. \& Schumaker T.T.S., 2010, Diagnoses of fipronil resistance in Brazilian cattle ticks (Rhipicephalus (Boophilus) microplus) using in vitro larval bioassays. Veterinary Parasitology 173: 300-306.

Díaz L.E., Camberos P.E., Herrera C.G.A., Espinosa M.E., Andrews H.E.; Buelnas P.N.A., Ortega A.G. \& Velázquez M.M., 2019, Development of essential oil-based phytoformulations to control the cattle tick Rhipicephalus microplus using a mixture design approach. Experimental Parasitology 201: 26-33.

Dolya V.S., Mozul V.I. \& Karpenko V.V., 1999, Research od ether oils of plants of genus metha. News of pharmacy 2(20): 158-159 (in Russian).

Dorla E., Grondin I., Hue T., Clerc P., Dumas S., GauvinBialecki A. \& Laurent P., 2019, Traditional uses, antimicrobial and acaricidal activities of 20 plants selected among Reunion Island's flora. South African Journal of Botany 122: 447-456.

Dumont P., Chester T.S., Gale B., Soll M., Fourie J.J. \& Beugnet F., 2015, Acaricidal efficacy of a new combination of fipronil and permethrin against Ixodes ricinus and Rhipicephalus sanguineus ticks. Parasites \& Vectors 8, Article number: 51.

El-Seedi H.R., Azeem M., Khalil N.S., Sakr H.H., Khalifa S.A.M., Awang K., Saeed A., Farag M.A., AlAjmi M.F., Palsson K. \& Borg-Karlson A.-K., 2017, Essential oils of aromatic Egyptian plants repel nymphs of the tick Ixodes ricinus (Acari: Ixodidae). Experimental and Applied Acarology 73: 139-157.

Elmhalli F., Garboui S.S., Borg-Karlson A.-K., Mozuraitis R., Baldauf S.L. \& Grandi G., 2019, The repellency and toxicity effects of essential oils from the Libyan plants Salvadora persica and Rosmarinus officinalisss against nymphs of Ixodes ricinus. Experimental and Applied Acarology 77: 585-599.

Emchuk E.M., 1960, Fauna of Ukraine. Ixodid ticks. AN Ukraine, Kyiv (in Ukrainian). 
Fischer V.L., Heidmann M.J., Faria E.F., Rizzi V.G., Bragaglia G.N., Nascimento C.G. \& de Castro B.G., 2013, Acaricidal efficacy of topical formulation of fipronil in naturally infested dogs in Amazonic region, Brazil. Revista Brasileira de Parasitologia Veterinaria 22: 186-188.

Gray J.S., Dautel H., Estrada-Peña A., Kahl O. \& Lindgren E., 2009, Effects of Climate Change on Ticks and TickBorne Diseases in Europe. Interdisciplinary Perspectives on Infectious Diseases 2009: ID 593232.

Jaenson T.G.T., Carboui S. \& Palsson K., 2006, Repellency of oils of lemon eucalyptus, geranium, and lavender and the mosquito repellent MyggA natural to Ixodes ricinus (Acari : Ixodidae) in the laboratory and field. Journal of Medical Entomology 43: 731-736.

Jaenson T.G.T., Palsson K. \& Borg-Karlson A.K., 2005, Evaluation of extracts and oils of tick-repellent plants from Sweden. Medical and Veterinary Entomology 19: 345-352.

Jia M., He Q., Wang W., Dai J. \& Zhu L., 2018, Chemical composition and acaricidal activity of Arisaema anurans essential oil and its major constituents against Rhipicephalus microplus (Acari: Ixodidae). Veterinary Parasitology 261: 59-66.

Korniyevsky Y.I., Pasenchenko, V.G., Korniyevska E.O. \& Karpun E.O., 2019, Chromato-mass spectrometric characteristics of tincture Thymus serpyllum L., [in:] Conduct of Modern Science - 2019. Sheffield. Science and Education LTD, 2019: 9-15 (in Ukrainian).

Lindgren E., Tälleklint L. \& Polfeldt T., 2000, Impact of Climatic Change on the Northern Latitude Limit and Population Density of the Disease-Transmitting European Tick Ixodes ricinus. Environmental Health Perspectives 108: 119-123.

Malik A., Afshan K., Razzaq A., Fatima Z., Hussain M. \& Firasat S., 2021, Comparative Efficacy of Synthetic Acaricides Against Tick Infestations in Goats. Kafkas Universitesi Veteriner Fakultesi Dergisi 27: 159-164.

Mangia C., Vismarra A., Genchi M., Epis S., Bandi C., Grandi G., Bell-Sakyi L., Otranto D., Passeri B. \& Kramer L., 2018, Exposure to amitraz, fipronil and permethrin affects cell viability and $\mathrm{ABC}$ transporter gene expression in an Ixodes ricinus cell line. Parasites \& Vectors 11, Article number: 437.

Matos R.S., Oliveira P.R. de Coelho L., Paula L.G.F., de Zeringota, V., Silva, B.C., Monteiroc C., Daemonb E., Camargo-Mathiasa M.I., 2020, Thymol: Effects on reproductive biology and Gene's organ morphology in Rhipicephalus sanguineus sensu lato engorged females (Acari: Ixodidae). Ticks and Tick-borne Diseases 11: 101308.

Monteiro C.M., de Maturano R., Daemon E., Aragao Catunda-Junior F.E., Calmon F., Senra T., Faza A. \& de
Carvalho M.G., 2012, Acaricidal activity of eugenol on Rhipicephalus microplus (Acari: Ixodidae) and Dermacentor nitens (Acari: Ixodidae) larvae. Parasitology Research 111: 1295-1300.

Naqqash M.N., Gokce A., Bakhsh A. \& Salim M., 2016, Insecticide resistance and its molecular basis in urban insect pests. Parasitology Research 115: 1363-1373.

Novato T.P.L., Araújo L.X., Oliveira de Monteiro C.M., Maturano R., de Oliveira Souza Senra T., da Silva Matos R., Gomes A.G., de Carvalho M.G. \& Daemon E., 2015, Evaluation of the combined effect of thymol, carvacrol and (E)-cinnamaldehyde on Amblyomma sculptum (Acari: Ixodidae) and Dermacentor nitens (Acari: Ixodidae) larvae. Veterinary Parasitology 212: 331-335.

Nwanade C.F., Wang M., Wang T., Yu,Z. \& Liu J., 2020, Botanical acaricides and repellents in tick control: current status and future directions. Experimental and Applied Acarology 81: 1-35.

Ogden N.H. \& Lindsay L.R., 2016, Effects of Climate and Climate Change on Vectors and Vector-Borne Diseases: Ticks Are Different. Trends in Parasitology 32: 646-656. Oliveira P.R. de, Bechara G.H. \& Camargo-Mathias M.I., 2008, Evaluation of cytotoxic effects of fipronil on ovaries of semi-engorged Rhipicephalus sanguineus (Latreille, 1806) (Acari : Ixodidae) tick female. Food and Chemical Toxicology 46: 2459-2465.

Peixoto M.G., Costa-Júnior L.M., Blank A.F., da Silva Lima A., Menezes T.S.A., de Alexandria Santos D., Alves P.B., de Holanda Cavalcanti S.C., Bacci L., de Fátima ArrigoniBlank M., 2015, Acaricidal activity of essential oils from Lippia alba genotypes and its major components carvone, limonene, and citral against Rhipicephalus microplus. Veterinary Parasitology 210: 118-122.

Pereira M.C., Gasparotto A.E., Paneczko Jurgilas J., Coelho da Silva L.A., Pereira M.C., Santos Silveira S., Neigri Silva T., Arnosti A., Camargo-Mathias M.I., 2017, Detrimental effect of deltamethrin on the central nervous system (synganglion) of Rhipicephalus sanguineus ticks. Experimental and Applied Acarology 71 159-169.

Pichersky E. \& Gershenzon J., 2002, The formation and function of plant volatiles: perfumes for pollinator attraction and defense. Current Opinion in Plant Biology 5: 237-243.

Rashidi S., Eikani M. \& Ardjmand M., 2019, Extraction of Hyssopus officinalisss L. essential oil using instant controlled pressure drop process. Journal of Chromatography 1579: 9-19.

Rulison E.L., Kuczaj I., Pang G., Hickling G.J., Tsao J.I. \& Ginsberg H.S., 2013, Flagging versus dragging as sampling methods for nymphal Ixodes scapularis (Acari: Ixodidae). Journal of Vector Ecology 38: 163-167. 
Stefanidesova K., Skultety L. \& Sparagano O.A.E., 2017, The repellent efficacy of eleven essential oils against adult Dermacentor reticulatus ticks. Ticks and Tick-borne Diseases 8: 780-786.

The Stockholm Convention on Persistent Organic Pollutants was adopted on 22 May 2001 in Stockholm, Sweden. The Convention entered into force on 17 May 2004.

Thorsell W., Mikiver A. \& Tunon H., 2006, Repelling properties of some plant materials on the tick Ixodes ricinus L. Phytomedicine 13: 132-134.

Voronova N.V, Horban V.V \& Bohatkina V.A., 2019, The efficacy of natural acaricide application against ixodidae (Ixodes ricinus). Acta Biologica Ukrainica 1: 31-39 (in Ukrainian).

Voronova N.V., Gorban V.V., Bogatkina V.A. \& Lyginin N.S., 2016, Investigation and detection of new methods of controlling and abolition the ticks in urbanized landscapes of Zaporozhzhya region, [in:] Sciences, T.N.E.C. on B. and M., The Ninth European Conference on Biology and Medical Sciences: 109-111.
Voronova N.V., Gorban V.V., Beletsky G.V., Drul O.S. \& Luginin N.S., 2009, Epidemiological value of bloodsicking arthropods of recreational zones of northwest priazovye. Bulletin of Zaporizhzhia National University 2: 126-131 (in Ukrainian).

Voronova N.V., Gorban V.V. \& Lyginin N.S., 2011, Distribution of tick on the biogeocenoses wood plantings of zaporizhzhya area. Bulletin of Zaporizhzhia National University 1: 17-25 (in Ukrainian).

Wong C., Crystal K. \& Coats J., 2021, Three molecules found in rosemary or nutmeg essential oils repel ticks (Dermacentor variabilis) more effectively than DEET in a no-human assay. Pest Management Science 77(3): 1348-1354.

Xie Y.J., Jin H., Yang X., Gu Q. \& Zhang D., 2020, Toxicity of the essential oil from Thymus serpyllum and thymol to larvae and pupae of the housefly Musca domestica L. (Diptera: Muscidae). Environmental Science and Pollution Research 27: 35330-35340. 